\title{
Complete Lymph Node Dissection in Melanoma: A Systematic Review and Meta-Analysis
}

\author{
ALBERTO FALK DELGADO $^{1 *}$ and ANNA FALK DELGADO ${ }^{2 *}$ \\ ${ }^{1}$ Plastic and Reconstructive Surgery, Department of Surgical Sciences, Uppsala University, Uppsala, Sweden; \\ ${ }^{2}$ Department of Clinical Neuroscience, Karolinska Institute, Stockholm, Sweden
}

\begin{abstract}
Background: The aim of this meta-analysis was to estimate the survival after immediate complete lymph node dissection (CLND) compared to observation only $(O O)$ or delayed CLND in patients with melanoma and lymph node metastasis. Materials and Methods: A systematic search was performed in: PubMed, Web of Science, Cochrane Library, CINAHL, Clinical trials and Embase. Eligible studies were randomized controlled trials (RCTS) comparing: CLND with OO, or immediate CLND with delayed CLND. Results: Four $R C T$ s were included. There was no difference in melanomaspecific survival (MSS) (HR=0.91, 95\% CI=0.77-1.08, $p=0.29$ ). In a sensitivity analysis, MSS was higher after immediate CLND compared to delayed CLND in patients with nodal metastasis $(H R=0.63$, 95\% CI=0.35-0.74, $p=0.0004)$ without evidence of heterogeneity. Conclusion: CLND appears to have no additional survival benefit after SNB compared to OO. However, subgroup analysis suggests a time-dependent benefit for early surgical lymph node removal compared to delayed or none.
\end{abstract}

Complete lymph node dissection (CLND) is a cornerstone in the treatment of patients with cutaneous malignant melanoma (MM) with a positive sentinel node biopsy (SNB), despite no clear evidence supporting this procedure. The rationale for CLND is based on the concept that extensive surgical resection reduces tumor burden, prohibits further metastasis and thereby prolongs survival. An additional advantage is the possibility for further staging of the disease. Axillary CLND includes anatomical levels I-III; from the lower edge of the pectoralis minor muscle to the superior aspect of the same muscle.

\footnotetext{
*These Authors contributed equally to this study.

Correspondence to: Alberto Falk Delgado, Ing. 78/79 Plastikmottagningen, Akademiska Sjukhuset, 75185, Uppsala, Sweden. E-mail: Alberto.falk-delgado@surgsci.uu.se
}

Key Words: Complete lymph node dissection, melanoma, review.
Axillary CLND is associated with major patient morbidity such as seroma formation, infection and lymphedema (1).

Previous randomized controlled trials (RCTs) have compared the therapeutic value of immediate CLND compared to delayed CLND at clinical diagnosis of regional lymph node metastasis in patients with MM, without showing improved survival after immediate CLND (2-6). These previous studies however lack generalizability to today's management of patients with MM due to the current practice of initial SNB for $>$ T1b melanomas $(\leq 1.0 \mathrm{~mm}$ thick with presence of ulceration or mitoses). Data from two randomized controlled trials have now emerged comparing immediate CLND with observation only (OO) in patients with MM after positive SNB showing evidence of improved disease-free survival (DFS) after immediate CLND $(7,8)$. One major issue with the two latest RCTs are related to their inclusion within 120-140 days after a positive SNB. There might be a time-dependent benefit of lymph node surgery which is undetected with this wide interval between biopsy and surgery (9). A pooled analysis is warranted to provide a more accurate estimation of the treatment benefit for lymph node surgery in patients with $\mathrm{MM}$ and nodal metastases in order to assess the clinical role for CLND, and to assess if there might be a time dependency to the treatment benefit.

The aim of this meta-analysis was to estimate the survival after immediate CLND compared to OO or delayed CLND in patients with $\mathrm{MM}$ and regional lymph node metastasis in order to elucidate the role for regional lymph node surgery in patients with melanoma.

\section{Materials and Methods}

This study was conducted according to the PRISMA statement for reporting systematic reviews and meta-analyses of studies that evaluate health care interventions: explanation and elaboration (10). This systematic review and meta-analysis was registered in the PROSPERO database (CRD42017072773).

Data sources. Potentially eligible studies, including grey literature, were searched for from inception to July 16th, 2017, in the 
Table I. Study characteristics.

\begin{tabular}{|c|c|c|c|c|c|c|c|c|c|c|c|}
\hline $\begin{array}{l}\text { First author, } \\
\text { year (Ref) }\end{array}$ & $\begin{array}{c}\text { Data } \\
\text { acquisition }\end{array}$ & $\begin{array}{c}\text { Accrual } \\
\text { period }\end{array}$ & $\begin{array}{c}\text { Nodal } \\
\text { metastasis } \\
\text { detection } \\
\text { method }\end{array}$ & $\begin{array}{l}\text { Number of } \\
\text { patients } \\
\text { included } \\
\text { in the } \\
\text { analysis }\end{array}$ & $\begin{array}{l}\text { Intervention } \\
\text { group }\end{array}$ & $\begin{array}{l}\text { Control } \\
\text { group }\end{array}$ & $\begin{array}{c}\text { Follow-up } \\
\text { (mean/ } \\
\text { median), } \\
\text { months }\end{array}$ & $\begin{array}{c}\text { Primary } \\
\text { MM } \\
\text { site }\end{array}$ & $\begin{array}{c}\text { MM } \\
\text { thickness } \\
(\mathrm{mm})\end{array}$ & $\begin{array}{c}\text { Mean age } \\
\text { (CLND/OO, } \\
\text { delayed } \\
\text { CLND), } \\
\text { years }\end{array}$ & $\begin{array}{c}\text { Mean } \\
\text { Breslow } \\
\text { thickness } \\
\text { (CLND/OO, } \\
\text { delayed } \\
\text { CLND), mm }\end{array}$ \\
\hline $\begin{array}{l}\text { Faries et al. } \\
2017,(7)\end{array}$ & $\begin{array}{l}\text { Whole } \\
\text { study }\end{array}$ & $\begin{array}{l}2004- \\
2014\end{array}$ & $\begin{array}{c}\text { SNB or SNB } \\
\text { and PCR }\end{array}$ & 1755 & $\mathrm{CLND}^{\mathrm{b}}$ & $\begin{array}{l}\text { OO (after } \\
\text { SNB/PCR) }\end{array}$ & $\begin{array}{c}43 \\
(\text { median})\end{array}$ & $\begin{array}{c}\mathrm{HN} / \mathrm{AL} / \\
\text { TR }\end{array}$ & $1.2-3.5$ & $52.5 / 53.2$ & $2.8 / 2.7$ \\
\hline $\begin{array}{l}\text { Leiter } \text { et al. } \\
2016,(8)\end{array}$ & $\begin{array}{l}\text { Whole } \\
\text { study }\end{array}$ & $\begin{array}{l}2006- \\
2014\end{array}$ & SNB & 473 & CLND $^{c}$ & $\begin{array}{c}\text { OO (after } \\
\text { SNB) }\end{array}$ & $\begin{array}{c}35 \\
\text { (median) }\end{array}$ & $\mathrm{AL} / \mathrm{TR}$ & $\begin{array}{l}\text { No } \\
\text { restriction }\end{array}$ & $57.0 / 56.0$ & $2.4 / 2.4$ \\
\hline $\begin{array}{l}\text { Morton et al. } \\
2006,(14)\end{array}$ & Subgroup & $\begin{array}{l}1994- \\
2002\end{array}$ & $\begin{array}{l}\text { SNB, CLND } \\
\text { or clinical } \\
\text { detection }\end{array}$ & 200 & CLND $^{d}$ & $\begin{array}{l}\text { Delayed } \\
\text { CLNDf }\end{array}$ & $\begin{array}{c}60 \\
(\text { median) }\end{array}$ & $\begin{array}{c}\mathrm{HN} / \mathrm{AL} / \\
\text { TR }\end{array}$ & $1.2-3.5$ & $49.4 / 54.1$ & $2.2 / 2.3$ \\
\hline $\begin{array}{l}\text { Cascinelli } \\
\text { et al. } \\
1998,(5)\end{array}$ & Subgroup & $\begin{array}{l}1994- \\
2002\end{array}$ & $\begin{array}{l}\text { CLND and } \\
\text { clinical } \\
\text { detection }^{\mathrm{a}}\end{array}$ & 63 & CLND $^{\mathrm{e}}$ & $\begin{array}{l}\text { Delayed } \\
\text { CLND }^{f}\end{array}$ & $\begin{array}{c}132 \\
\text { (mean) }\end{array}$ & TR & $>1.5$ & NA/NA & NA/NA \\
\hline
\end{tabular}

AL: Arm or leg, CLND: complete lymph node dissection, HN: head and neck, OO: observation only, SNB: sentinel node biopsy, PCR: polymerase chain reaction, TR: trunk, OBS: observation, MM: malignant melanoma. ${ }^{a}$ After observation. ${ }^{b}$ After positive SNB or SNB and PCR and within 140 days. ${ }^{\mathrm{c} A f t e r}$ positive SNB and within 120 days. ${ }^{\mathrm{d} A f t e r}$ positive SNB. ${ }^{\mathrm{e} A f t e r}$ MM wide excision. ${ }^{\mathrm{f}}$ After MM wide excision and clinical nodal recurrence after observation.

following databases: PubMed, Web of Science, Cochrane Library, Cumulative Index to Nursing \& Allied Health Literature (CINAHL), Clinical trials and Embase. The search strategy was developed by two investigators with experience in literature searches and systematic reviews. The following free text terms were used: "melanoma", "surgery", and "randomized controlled trials". All search terms were expanded in the electronic search.

Eligibility criteria. Eligible RCTs compared immediate CLND with $\mathrm{OO}$ in patients with cutaneous MM and a prior positive SNB. Furthermore, RCTs comparing immediate CLND with delayed CLND presenting data from subgroups of patients with regionally metastasized MM were also eligible for inclusion. Included studies reported on one of the following survival outcomes: melanomaspecific survival (MSS), DFS/recurrence-free survival (RFS) and disease control rate in regional nodes. No language restrictions were applied in the search. Retrieved hits were evaluated for potential inclusion by one investigator, with potential relevant studies discussed with a second investigator.

Primary and secondary outcomes. The primary outcomes of the study were: MSS after immediate CLND compared with OO in patients with melanoma and a positive SNB; MSS after immediate CLND compared to delayed CLND. Secondary study outcomes were: DFS and DCR in the above groups plus adverse events after CLND for regionally metastasized MM.

Data extraction. Data were extracted by two investigators. The following parameters were extracted from each manuscript and supplementary material: first author's name, year of publication, number of randomized population, number of patients included in the analysis, Breslow thickness in $\mathrm{mm}$, primary cutaneous site of MM, median/mean age. Survival data were extracted from KaplanMeier curves, text or tables where feasible. Data on adverse events was taken from the manuscript or supplementary material. Risk of bias assessment was performed by two investigators.

Statistical analysis. Survival data (time to event data - time to death/progression/recurrence, MSS, DFS and DCR) were calculated as Hazard ratios (HR) with $95 \%$ confidence intervals (CI), for immediate CLND versus OO/delayed CLND. For studies not reporting HRs, HRs were estimated as previously described by Tierney et al. (11). A sensitivity analysis was conducted stratifying RCTs for different control groups: those that randomized patients to $\mathrm{OO}$ and those that randomized patients to delayed CLND. HRs from each RCT were combined implementing Yusuf et al.'s method using the observed minus expected $(\mathrm{O}-\mathrm{E})$ and Variance statistics (12). To assess for robustness of the results we also calculated HRs using the generic inverse variance method applying the random-effects model (13). For all calculations, the per-protocol population was assessed. Heterogeneity was explored using the $\chi^{2}$ (cut-off at $<0.1$ ) and $\mathrm{I}^{2}$ (cut off $>50 \%$ ). $\chi^{2}$ was used to test whether observed differences in results were compatible with chance alone and $\mathrm{I}^{2}$ was used to assess for the percentage of total variation across studies due to heterogeneity. RevMan 5.3 (Review Manager, Version 5.3, Copenhagen, The Cochrane Collaboration) software was used for all calculations.

\section{Results}

The search identified 1,354 records that were screened for possible inclusion by title assessment. After excluding 1,343 irrelevant titles, a total of 11 abstracts were reviewed, out of which eight underwent full-text evaluation. Three full-text studies were excluded due to incomplete reporting of survival data for patients with regional metastasis. One study was excluded due to duplicate/follow-up cohorts. Ultimately 
Table II. Risk of bias assessment.

\begin{tabular}{|c|c|c|c|c|c|c|c|}
\hline $\begin{array}{l}\text { First author, } \\
\text { Year (Ref) }\end{array}$ & $\begin{array}{l}\text { Random } \\
\text { sequence } \\
\text { generation }\end{array}$ & $\begin{array}{l}\text { Allocation } \\
\text { concealment }\end{array}$ & $\begin{array}{l}\text { Blinding of } \\
\text { participants } \\
\text { and personnel }\end{array}$ & $\begin{array}{l}\text { Blinding of } \\
\text { outcome } \\
\text { assessment }\end{array}$ & $\begin{array}{c}\text { Incomplete } \\
\text { outcome } \\
\text { data }\end{array}$ & $\begin{array}{l}\text { Selective } \\
\text { reporting }\end{array}$ & $\begin{array}{l}\text { Other } \\
\text { bias }\end{array}$ \\
\hline Faries et al. (7), 2017 & High risk & Unclear risk & High risk & High risk & Low risk & Low risk & Low risk \\
\hline Leiter et al. (8), 2016 & Low risk & Low risk & High risk & High risk & Low risk & Low risk & Low risk \\
\hline Morton et al. (14), 2006 & Low risk & Low risk & High risk & High risk & Low risk & Low risk & Low risk \\
\hline Cascinelli et al. (5), 1998 & High risk & Unclear risk & High risk & High risk & Low risk & Unclear risk & Low risk \\
\hline
\end{tabular}

Table III. Treatment benefit of complete lymph node dissection.

\begin{tabular}{|c|c|c|c|c|c|c|}
\hline & \multirow[b]{2}{*}{$\begin{array}{l}\text { No. of } \\
\text { studies }\end{array}$} & \multirow[b]{2}{*}{$\begin{array}{l}\text { No. of patients included } \\
\text { in the analysis }\end{array}$} & \multirow[b]{2}{*}{$\mathrm{HR}(95 \% \mathrm{CI})$} & \multirow[b]{2}{*}{$p$-Value } & \multicolumn{2}{|c|}{ Heterogeneity } \\
\hline & & & & & $\chi^{2}$ & $\mathrm{I}^{2}(\%)$ \\
\hline \multicolumn{7}{|l|}{ Main analysis } \\
\hline MSS after immediate CLND vs. OO or delayed CLND & 4 & 2491 & $0.91(0.77-1.08)$ & 0.29 & 0.0008 & 75 \\
\hline \multicolumn{7}{|l|}{ Sensitivity analysis } \\
\hline MSS after immediate CLND vs. OOa & 2 & 2268 & $1.06(0.87-1.28)$ & 0.57 & 0.63 & 0 \\
\hline $\begin{array}{l}\text { MSS after immediate CLND (nodal metastasis) vs. } \\
\text { delayed CLND (clinical nodal recurrence) }\end{array}$ & 2 & 263 & $0.51(0.35-0.74)$ & 0.0004 & 0.89 & 0 \\
\hline DFS after immediate CLND vs. OO or delayed CLND & 3 & 2428 & $0.80(0.71-0.90)$ & 0.0004 & 0.06 & 65 \\
\hline NR after immediate CLND vs. $\mathrm{OO}^{\mathrm{a}}$ & 2 & 2268 & $0.63(0.48-0.82)$ & 0.0005 & 0.97 & 0 \\
\hline
\end{tabular}

CLND: Complete lymph node dissection, HR: hazard ratio, DFS: disease free survival, NR: nodal recurrence, MSS; melanoma-specific survival, No: Number, OO: observation only. ${ }^{\text {an }}$ patients with positive sentinel node biopsy (SNB), or negative SNB but positive polymerase chain reaction (PCR).

four studies met all inclusion criteria, and were therefore included in the meta-analysis $(5,7,8,14)$.

Characteristics of the included studies are presented in Table I. Two RCTs compared immediate CLNB with OO in patients with positive SNB $(7,8)$.Two RCTs compared immediate CLND with delayed CLND and presented data on subgroups of patients with regional lymph node metastasis at the immediate CLND and clinical nodal recurrence at the delayed CLND $(5,14)$. The study by Cascinelli et al. did not perform SNB (5). Instead they performed immediate CLND and delayed CLND at signs of clinical recurrence. The patients needed to have their biopsy within 6 weeks of final treatment. However, only the subgroup of patients with nodal metastases were included in the meta-analysis. In total, 2491 patients were included in the meta-analysis population.

The risk of bias assessment is provided in Table II. Adequate randomization and concealed allocation were performed in two of the RCTs $(5,14)$. None of the studies were blinded for participants nor assessment outcome. None of the studies had bias related to attrition bias, such as bias related to incomplete outcome data. Three of the studies had low risk of bias for selective reporting of outcome data (7, $8,14)$ and one study had high risk bias (5).

Main analysis. There was no difference in the primary outcome, MSS, when comparing immediate CLND with OO/delayed CLND (Table III). Evidence of heterogeneity was found in the analysis, $\chi^{2}=0.0008, \mathrm{I}^{2}=75 \%$. The secondary outcome, DFS, increased after immediate CLND compared with OO/delayed CLND ( $p=0.0004)$. The disease control rate was improved by immediate CLND compared to OO $(p=0.0005)$.

Sensitivity analysis. Stratifying studies for subgroups of RCTs comparing immediate CLND with OO showed similar results as the main analysis, with a HR for death of 1.06 (95\% CI $0.87-1.28, p=0.57)$. However, heterogeneity decreased to $\chi^{2}=0.63, \mathrm{I}^{2}=0 \%$. The subpopulations from the study by Morton et al. consisted of patients that underwent immediate CLND after positive SNB, and delayed CLND at signs of clinical recurrence (14). The subpopulations from the study by Cascinelli et al. included only patients with nodal metastases in patients undergoing immediate CLND or delayed CLDN at 
signs of recurrence without any patients undergoing SNB (5). In the meta-analysis subgroup of patients from studies comparing immediate CLND (study subgroup including patients with lymph node metastasis) with delayed CLND (study subgroup including patients with clinical lymph node metastasis), MSS was higher after immediate CLND $(p=0.0004)$ with no statistical heterogeneity $\left(\chi^{2}=0.89, \mathrm{I}^{2}=0 \%\right)$.

Adverse events. Two of the studies reported on adverse events. In that of Faries et al. lymphedema was reported in $24 \%$ of the patients undergoing CLND (7). Similarly, Leiter et al. reported $24 \%$ adverse events following surgery including lymphedema, seroma formation, infection, lymph fistula and delayed wound healing (8).

\section{Discussion}

This meta-analysis and systematic review based on available evidence shows no additional survival benefit of CLND compared to OO/delayed CLND after immediate SNB in patients with regional MM lymph node metastasis. This is the first meta-analysis to the best of our knowledge suggesting time-dependent disease-specific survival advantage related to early/immediate lymph node surgery, explaining the lack of improved MSS after CLND performed after immediate SNB.

Strengths of this meta-analysis are pertinent to a broad electronic systematic search aiming to include all randomized controlled trials conducted on patients with MM and lymph node metastasis. This meta-analysis was registered in Prospero. To our knowledge, this is the first meta-analysis to scrutinize the treatment effect of CLND in patients with MM and lymph node metastasis including relevant RCTs reflecting todays clinical management of patients with MM metastasis.

Analyzing the differences in MSS between the main analysis including all four RCTs and the sensitivity-analysis stratifying studies based on a control group (OO or delayed CLND), there seems to be an advantage to performing an immediate CLND as compared to a delayed CLND in patients with MM metastases.

Based on our subgroup analysis with subpopulations of patients from Morton et al. (14) and Cascinelli et al. (5) with nodal metastasis, one can attribute the potential treatment benefit of lymph node surgery to the fact that all included patients had some form of immediate lymph node surgery. In the study of Morton et al., patients were subject to primary SNB before CLND compared to delayed CLND, and in that by Cascinelli et al., patients underwent immediate CLND compared to delayed CLND. No SNB was performed in the immediate subgroup analyzed in the study by Cascinelli et al., however, they found an improved survival in the immediate CLND group compared to delayed in the population with nodal metastases. Furthermore, only patients receiving their final treatment within 6 weeks from biopsy were included. Although Cascinelli et al. do not present the exact timing for immediate and delayed CLND, the median time from MM excision to nodal metastasis was 8.3 months, leaving a potential interval of more than 6 months between the CLND procedures in each treatment arm. This window, although not directly specified in the study, seems to account for the difference in survival benefit between the two treatment arms. CLND after 8.3 months yielded lower MSS compared to immediate CLND. Hence, the fact that the two most recent studies by Faries et al. (7) and Leiter et al. (8) allowed patients to fall into the category of 'immediate' CLND for as long as up to 120-140 days after excision might be above the therapeutic upper boundary for a clinical benefit. However, all patients in the two most recent studies were subject to pre-randomization positive SNB, possibly mimicking a situation of true early surgical resection earning the epithet of an immediate procedure, which also might explain the lack of difference in MSS between the two treatment arms. Considering that MM is a highly aggressive tumor with the propensity for early metastasis, our results suggest that the surgical treatment benefit for a patient with regional MM metastases lies not in the procedure itself (SNB or CLND) but in its timing. Given the lack of improved MSS found by Faries et al. (7) and Leiter et al. (8), the difference in survival compared to the subpopulations in Morton et al. and Cascinelli et al. $(5,14)$. may be explained by the timing of the procedure rather than the extent of the surgery. MSS was improved in both latter studies in the subgroups of patients with nodal metastases. In the studies by Leiter et al. and Faries et al., there was no improved MSS after a previous SNB. Based on this, there appears to be no additional survival benefit after a primarily conducted SNB.

The limitations of the study are related to the trials by Cascinelli et al. and Morton et al. comparing immediate CLND with delayed CLND which provide evidence for improved MSS for patients with nodal metastases undergoing immediate CLND. These data suffer from two main problems: The data need to be interpreted cautiously since patients were not subject to true randomization but rather based on a post hoc analysis. Furthermore, the data from Cascinelli et al. are dated, since SNB is now well established in clinical practice.

Significant adverse events were reported in $24 \%$ of patients undergoing CLND in two of the RCTs. However, none of the studies reported on direct surgical complications, such as injuries to the thoracodorsal nerve, the long thoracic nerve or vessel injuries. De Vries et al. reported worse quality of life in patients undergoing CLND compared to SNB (15), however, none of the included RCTs reported on this aspect. Surgical co-morbidities are an important aspect when discussing procedural approaches with patients and both physical and psychological aspects have to be accounted for. 
An important conclusion that can be drawn from this meta-analysis is that despite improved DFS, CLND does not appear to improve MSS in patients with MM and preceding SNB. This suggests that DFS is a poor surrogate marker for survival in patients with MM. It is unclear whether improved DFS after CLND compared to observation translates into improved survival in combination with modern drug therapy such programmed cell-death protein (PD-1) inhibitors (16).

Future studies should address the time aspect in surgical regional lymph node treatment, irrespective of surgical technique, in patients with MM regional metastasis.

Based on current available evidence, there seems to be no additional MSS benefit of CLND compared to OO after immediate SNB in patients with regional lymph node metastasis from MM. However, there appears to be a timedependent disease-specific survival advantage related to early/ immediate lymph node surgery compared to delayed or none.

\section{Funding}

None.

\section{Acknowledgements}

The Authors would like to thank the patients who give us inspiration to improve treatments.

\section{References}

1 Morton DL, Cochran AJ, Thompson JF, Elashoff R, Essner R, Glass EC, Mozzillo N, Nieweg OE, Roses DF, Hoekstra HJ, Karakousis CP, Reintgen DS, Coventry BJ and Wang HJ: Sentinel node biopsy for early-stage melanoma: accuracy and morbidity in MSLT-I, an international multicenter trial. Ann Surg 242(3): 302-111; discussion 11-13, 2005.

2 Balch CM, Soong SJ, Bartolucci AA, Urist MM, Karakousis CP, Smith TJ, Temple WJ, Ross MI, Jewell WR, Mihm MC, Barnhill RL and Wanebo HJ: Efficacy of an elective regional lymph node dissection of 1 to $4 \mathrm{~mm}$ thick melanomas for patients 60 years of age and younger. Ann Surg 224(3): 255-263; discussion 63-66, 1996

3 Sim FH, Taylor WF, Pritchard DJ and Soule EH: Lymphadenectomy in the management of stage I malignant melanoma: a prospective randomized study. Mayo Clin Proc 61(9): 697-705, 1996.

4 Veronesi U, Adamus J, Bandiera DC, Brennhovd O, Caceres E, Cascinelli N, Claudio F, Ikonopisov RL, Javorski VV, Kirov S, Kulakowski A, Lacour J, Lejeune F, Mechl Z, Morabito A, Rodé I, Sergeev S, van Slooten E, Szczygiel K, Trapeznikov NN and Wagner RI: Delayed regional lymph node dissection in stage I melanoma of the skin of the lower extremities. Cancer 49(11): 2420-2430, 1982.

5 Cascinelli N, Morabito A, Santinami M, MacKie RM and Belli F: Immediate or delayed dissection of regional nodes in patients with melanoma of the trunk: a randomised trial. WHO Melanoma Programme. Lancet 351(9105): 793-796, 1998.

6 Lens MB, Dawes M, Goodacre T and Newton-Bishop JA: Elective lymph node dissection in patients with melanoma: systematic review and meta-analysis of randomized controlled trials. Arch Surg 137(4): 458-461, 2002.

7 Faries MB, Thompson JF, Cochran AJ andtbacka RH, Mozzillo N, Zager JS, Jahkola T, Bowles TL, Testori A, Beitsch PD, Hoekstra HJ, Moncrieff M, Ingvar C, Wouters MWJM, Sabel MS, Levine EA, Agnese D, Henderson M, Dummer R, Rossi CR, Neves RI, Trocha SD, Wright F, Byrd DR, Matter M, Hsueh E, MacKenzie-Ross A, Johnson DB, Terheyden P, Berger AC, Huston TL, Wayne JD, Smithers BM, Neuman HB, Schneebaum S, Gershenwald JE, Ariyan CE, Desai DC, Jacobs L, McMasters KM, Gesierich A, Hersey P, Bines SD, Kane JM, Barth RJ, McKinnon G1, Farma JM, Schultz E, Vidal-Sicart S, Hoefer RA, Lewis JM, Scheri R, Kelley MC, Nieweg OE, Noyes RD, Hoon DSB, Wang HJ, Elashoff DA and Elashoff RM: Completion dissection or observation for sentinel-node metastasis in melanoma. N Engl J Med 376(23): 2211-222, 2017.

8 Leiter U, Stadler R, Mauch C, Hohenberger W, Brockmeyer N, Berking C, Sunderkötter C, Kaatz M, Schulte KW, Lehmann P, Vogt T, Ulrich J, Herbst R, Gehring W, Simon JC, Keim U, Martus P,Garbe C and German Dermatologic Cooperative Oncology Group (DeCOG): Complete lymph node dissection versus no dissection in patients with sentinel lymph node biopsy positive melanoma (DeCOG-SLT): a multicentre, randomised, phase 3 trial. Lancet Oncol 17(6): 757-767, 2016.

9 Falk Delgado A and Falk Delgado A : Melanoma Sentinel-Node Metastasis. N Engl J Med 377(9): 891-892, 2017.

10. Liberati A, Altman DG, Tetzlaff J, Mulrow C, Gøtzsche PC, Ioannidis JPA, Clarke M, Devereaux PJ, Kleijnen J and Moher D: The PRISMA statement for reporting systematic reviews and metaanalyses of studies that evaluate health care interventions: explanation and elaboration. J Clin Epidemiol 62(10): e1-34, 2009.

11 Tierney JF, Stewart LA, Ghersi D, Burdett S and Sydes MR: Practical methods for incorporating summary time-to-event data into meta-analysis. Trials 8: 16, 2007.

12 Yusuf S, Peto R, Lewis J, Collins R and Sleight P: Beta blockade during and after myocardial infarction: an overview of the randomized trials. Prog Cardiovasc Dis 27(5): 335-371, 1985.

13 DerSimonian R and Laird N: Meta-analysis in clinical trials. Control Clin Trials 7: 177-3188, 1986.

14 Morton DL, Thompson JF, Cochran AJ, Mozzillo N, Elashoff R, Essner R, Nieweg OE, Roses DF, Hoekstra HJ, Karakousis CP, Reintgen DS, Coventry BJ, Glass EC and Wang H J: Sentinelnode biopsy or nodal observation in melanoma. N Engl J Med 355(13): 1307-1317, 2006.

15 de Vries M, Hoekstra HJ and Hoekstra-Weebers JE: Quality of life after axillary or groin sentinel lymph node biopsy, with or without completion lymph node dissection, in patients with cutaneous melanoma. Ann Surg Oncol 16(10): 2840-2847, 2009.

16 Hodi FS, O'Day SJ, McDermott DF, Weber RW, Sosman JA, Haanen JB, Gonzalez R, Robert C, Schadendorf D, Hassel JC, Akerley W, van den Eertwegh AJ, Lutzky J, Lorigan P, Vaubel JM, Linette GP, Hogg D, Ottensmeier CH, Lebbé C, Peschel C, Quirt I, Clark JI, Wolchok JD, Weber JS, Tian J, Yellin MJ, Nichol GM, Hoos A and Urba WJ: Improved survival with ipilimumab in patients with metastatic melanoma. N Engl J Med 363(8): 711-723, 2010.

Received September 7, 2017 Revised September 28, 2017 Accepted October 3, 2017 